\title{
The effect of blinks and saccadic eye movements on visual reaction times
}

\author{
MurRay Johns \\ Swinburne University of Technology, Melbourne, Victoria, Australia \\ and Optalert Pty Ltd, Melbourne, Victoria, Australia \\ AND \\ Kate Crowley, Robert Chapman, \\ ANdrew TuCKer, AND Christopher Hocking \\ Optalert Pty Ltd, Melbourne, Victoria, Australia
}

\begin{abstract}
Vision is suppressed during blinks and saccadic eye movements. We hypothesized that visual reaction times (RTs) in a vigilance test would be significantly increased when a blink or a saccade happened to coincide with the stimulus onset. Thirty healthy volunteers each performed a visual RT test for 15 min while their eye and eyelid movements were monitored by a system of infrared reflectance oculography. RTs increased significantly, many by more than $200 \mathrm{msec}$, when a blink occurred between $75 \mathrm{msec}$ before and up to $150 \mathrm{msec}$ after the stimulus onset. A similar result was observed with saccades that started 75 to $150 \mathrm{msec}$ after the stimulus. Vision or attention was evidently inhibited before each blink and for longer than the saccades lasted. We suggest that visual suppression is involved in this process, which could explain some of the normal variability in RTs over periods of seconds that has not been adequately explained before.
\end{abstract}

Every time we blink, voluntarily or involuntarily, we cannot see, for two reasons: The upper eyelids cover the pupils and prevent most light from reaching the retina, and vision is suppressed centrally by a process called blink suppression (Volkmann, Riggs, \& Moore, 1980). This has been demonstrated by experiments that have bypassed the pupils, sending light to the retina via the roof of the mouth, which has shown that visual suppression still occurs during blinks (Volkmann et al., 1980). Functional MRI under those circumstances has indicated reduced neuronal activity that is specific to the visual system, which could account for the reduced sensitivity to light. There is also reduced activity in the parietal and prefrontal cortex, however, which suggests more general inhibition of awareness during blinks (Bristow, Haynes, Sylvester, Frith, \& Rees, 2005; Burr, 2005). Blink suppression begins before the start of each blink and ends after it finishes, lasting about 200-250 msec (Volkmann et al., 1980).

A similar process, called saccadic suppression, prevents us from being aware of the blurred images that would otherwise occur during rapid eye movements such as saccades, which we make as we look from one point to another (Volkmann, Schick, \& Riggs, 1968). Saccadic suppression is mainly central in origin, but it has an additional retinal component of control (Diamond, Ross, $\&$ Morrone, 2000). Saccadic suppression begins before the start of the saccade and ends after it, lasting about
100-150 msec (Volkmann et al., 1968). Blink and saccadic suppression share some mechanisms, but they are not identical (Ridder \& Tomlinson, 1997). Given that we usually blink about 15-20 times per min (Leigh \& Zee, 2006), involving perhaps $4 \mathrm{sec}$ of visual suppression, and that we have about 40 or more saccades per min, involving another 4 or $5 \mathrm{sec}$ of suppression, it is surprising that we are not aware of being functionally blind for $10 \%-15 \%$ of the time under normal circumstances. Our visual awareness is evidently extrapolated across periods that are "missing." The implications of this for psychomotor performance, as measured by visual reaction times and vision in daily life, have not been well canvassed.

Reaction time (RT) — how quickly someone responds to a visual stimulus that is presented repeatedly at random intervals - has long been used to measure psychomotor performance and brain function (Donders, 1868/1969; Luce, 1986). For example, many current theories of visual attention are based on changes in RT performance (Eriksen \& Eriksen, 1974; Posner, Snyder, \& Davidson, 1980). The resulting mean RT, RT variance, and response accuracy have often been used to infer "attention" or "distraction" effects (Van Breukelen et al., 1995). As part of our ongoing investigations into the variability of RTs, we wanted to know whether the visual suppression that is known to accompany blinks and saccades influences individual RTs under normal circumstances. Our hypothesis was that 
when the start of a stimulus happens to coincide with a blink or a saccade, that RT will be increased, because the stimulus will not be perceived until after the visual suppression has ended. Such an effect might explain some of the variance in RTs that has been attributed by others to intermittent mental "blocking" (Bills, 1931), "lapsing" as part of normal brain function (Dinges \& Kribbs, 1991; Williams, Lubin, \& Goodnow, 1959), or "noise" in the neuronal integrators that are involved in the perceptual decision-making process (Shadlen \& Newsome, 2001). To our knowledge, this has not been investigated previously.

The present experiment was facilitated by the development of a system of infrared (IR) reflectance oculography (Johns, Tucker, Chapman, Crowley, \& Michael, 2007) that enables eye and eyelid movements to be monitored continuously, without electrode attachment, while subjects perform a computer-based visual RT test, the Johns Test of Vigilance (JTV; Optalert Drowsiness Measurement System, Optalert Pty Ltd, Melbourne, Australia). We used this system with healthy volunteers to compare RTs with and without an associated blink or saccade that happened to coincide with the stimulus onset.

\section{METHOD}

\section{Visual RT Test}

The stimulus in the JTV was a brief change of shapes on a computer screen, in which three circles that were $20 \mathrm{~mm}$ in diameter became either squares or diamonds of the same size for a period of $400 \mathrm{msec}$ before reverting to circles. The shapes were white, with a thin black border and a 10-mm black cross in the center, and were displayed on a gray background. The circles were $200 \mathrm{~mm}$ apart, or $12.5^{\circ}$ apart when viewed from a distance of $0.5 \mathrm{~m}$. The stimulus thus involved a rapid change in the orientation of widely spaced lines that formed different shapes. Stimuli were presented at intervals that varied randomly between 5 and $15 \mathrm{sec}$. An average of approximately 85 stimuli were presented during the 15 -min test. The luminance of the stimulus was not measured directly. The $400-\mathrm{msec}$ duration of the stimulus was chosen because it is longer than the average blink, which is $265 \pm 57 \mathrm{msec}$, as measured by the system of IR reflectance oculography that was used here (Tucker \& Johns, 2005). If the stimulus was not perceived during that $400 \mathrm{msec}$, no valid response was possible; however, eyelid closure during blinks does not normally block vision directly for that long.

In the JTV, the respondent is asked to push a button, which is held in the hand, as quickly as possible after any change in the circles has been detected. The time between the onset of the stimulus and the pushbutton response (the raw RT) was measured automatically with an accuracy of $\pm 9 \mathrm{msec}$. An error of omission was said to occur when there was no pushbutton response within $2,000 \mathrm{msec}$ of the start of a stimulus. This time limit was somewhat arbitrary, but it was chosen to be several SDs above the "normal" range of RTs. An error of commission occurred when there was a response before the stimulus had started, or within the first $120 \mathrm{msec}$ of its onset, which was considered too soon to have been a physiological response (Brebner \& Welford, 1980).

\section{Monitoring Eye and Eyelid Movements}

While performing the JTV test, subjects wore a special glasses frame (Optalert Pty Ltd, Melbourne, Australia), much the same as one that would be worn normally with prescription lenses (Johns et al., 2007). A very small light-emitting diode (LED) that was attached to the frame emitted 500 pulses of IR light per sec (wavelength, $940 \mathrm{~nm}$ ), directed from below and in front of the eye in a $30^{\circ}$ cone of invisible light that was centered on the lower edge of the upper eyelid. The total amount of IR light that was reflected back from the eye and eyelid was measured during each pulse by a phototransistor next to the LED. There is always some other IR light that is present in the environment, originating from sunlight and/or artificial lights. This ambient IR light was measured by the phototransistor immediately before each pulse and then was subtracted from the combined amount that was measured during the pulse to overcome fluctuations in ambient IR light. The IR-light measurements and the output from the pushbutton were digitized every $2 \mathrm{msec}$. These digitized signals enabled the monitoring of movements of the eyes and eyelids, as well as the calculation of their timing, duration, and velocity using proprietary software (Johns et al., 2007). The JTV also recorded video images of the subject's face and eyes, but those images were not used for data analysis.

\section{Experimental Subjects and Protocol}

Thirty healthy volunteers ( 18 male, 12 female; mean age $=21.4$ years, range $=17-32$ years), who had normal visual acuity without correction, performed a 15-min visual RT test (JTV) during the morning after a self-reported "normal" night's sleep. All stimuli and RTs were identified by their starting times. Eye and eyelid movements and RT responses were stored in the same database, and the data surrounding each RT response were displayed on a monitor and scanned visually. Blinks and saccades that began within the period that began $300 \mathrm{msec}$ before and ended $300 \mathrm{msec}$ after the start of a stimulus were identified by their readily distinguishable waveforms. For the purposes of the present experiment, they were called coincident blinks or coincident saccades. The $\pm 300 \mathrm{msec}$ window was longer than the known time range for the effects of blink and saccadic suppression. For analysis, these coincident blinks and coincident saccades were separated into 75 -msec time bins, according to whether they began before or after the onset of a stimulus. All of those RTs were defined as coincident $R T \mathrm{~s}$. The difference between each coincident RT and its immediately preceding RT within the same subject was measured. The difference between consecutive RTs for all other cases, called noncoincident $R T \mathrm{~s}$, was also noted for comparison. The very short-term differences between consecutive RTs within $15 \mathrm{sec}$ were the primary data for this investigation. This eliminated longer term differences between subjects and the fluctuations in RT over a timescale of minutes to hours. The statistical significance of differences between groups of RT data was tested using several separate one-way ANOVAs with post hoc Tukey HSD tests, accepting significance at $p<.05$ in two-tailed tests. A paired $t$ test was used to test the significance of all differences between consecutive RTs. An unpaired (Student's) $t$ test was used to test the statistical significance of the difference between coincident RTs and noncoincident RTs. The experiment was approved by the relevant ethics committee of Swinburne University of Technology, Melbourne.

\section{RESULTS}

The number of stimuli that were presented to each subject varied between 81 and 90 during each JTV test. The mean of all 2,556 raw RTs was $390 \pm 103(S D)$ msec, the median was $376 \mathrm{msec}$, and the range was $142-970 \mathrm{msec}$. There were significant differences in raw RTs between subjects $[F(29,2526)=20.61, p<.0001]$. In 7 subjects, there were a total of nine errors of omission (no response within 2,000 msec) and one error of commission. Among all 2,556 raw RTs, 278 were longer than $500 \mathrm{msec}$, which some refer to as "lapses" in performance (Dinges \& Kribbs, 1991). One hundred ten of those lapses (39.6\%) were associated with a coincident blink or saccade, as were three $(33.3 \%)$ of the occasional errors of omission. Among all 30 subjects, 27 (90\%) had some coincident blinks and saccades. 


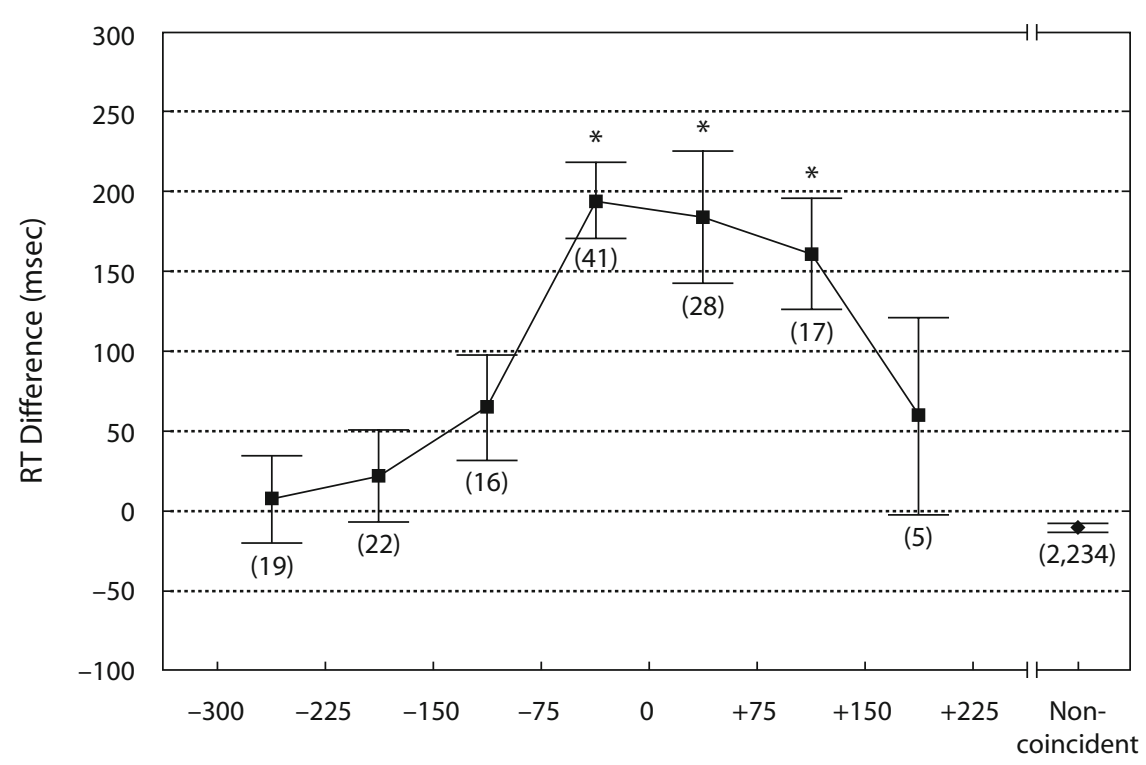

Time at Which Blinks Started in Relation to Stimulus Onset (msec)

Figure 1. The mean $( \pm S E)$ of differences between consecutive RTs that were associated with coincident and noncoincident blinks. The times that coincident blinks started are shown in relation to the stimulus onset (msec). The number of RTs in each category is shown in brackets. *Coincident RTs that were significantly different $(p<.001)$ from noncoincident RTs, according to post hoc Tukey HSD tests. All other differences were not significant $(p>.05)$.

The mean of all 2,515 differences between consecutive RTs within subjects was $0.5 \pm 130(S D) \mathrm{msec}(t=$ $-0.204, p=.84)$. A one-way ANOVA showed no significant difference between subjects $[F(29,2485)=0.04$, $p>$.9]. On 148 occasions, there was a coincident blink, and on another 133 occasions, there was a coincident saccade that happened to begin within $\pm 300 \mathrm{msec}$ of the start of a stimulus - that is, $11.2 \%$ of all 2,515 RTs were associated with either a coincident blink or a coincident saccade. The great majority of those ocular movements were presumably made spontaneously, as part of each subject's visual-search strategy during the vigilance task. The mean duration of coincident blinks was $276 \pm 95 \mathrm{msec}$, and that of coincident saccades was $59 \pm 15 \mathrm{msec}$, which are typical for alert subjects who are monitored by this system (Tucker \& Johns, 2005). The mean difference between consecutive RTs that were associated with either a coincident blink or a coincident saccade $(78 \pm 170 \mathrm{msec}$, $n=281$ ) was eight times greater than that for all noncoincident RTs $(-10 \pm 120 \mathrm{msec}, n=2,234)[t(2513)=$ $-11.1, p<.0001]$.

\section{Effect of Coincident Blinks on RTs}

A one-way ANOVA showed a significant overall difference between the noncoincident RTs and the coincident RTs in each time bin for coincident blinks $[F(7,2374)=$ $31.18, p<.001]$ (Figure 1 ). The +225 - to $+300-\mathrm{msec}$ time bin was omitted for lack of data. The difference between consecutive RTs for all noncoincident RTs is shown in Figure 1 for comparison.

Post hoc Tukey HSD tests showed that blinks that began during the $75 \mathrm{msec}$ before the stimulus ( -75 to 0 in Fig- ure 1) were associated with significantly increased RTs in comparison with noncoincident RTs $(p<.001)$. Similar results were observed for blinks that started within the 0 - to +75 -msec and +76- to +150 -msec time bins $(p<$ $.001)$. Coincident RTs in the $+150-$ to $+225-\mathrm{msec}$ bin and in other bins did not differ significantly from noncoincident RTs $(p>9)$. RTs thus increased significantly, often by $200 \mathrm{msec}$ or more, when they happened to be associated with blinks that started during the period from $75 \mathrm{msec}$ before to $150 \mathrm{msec}$ after the stimulus onset. A 200-msec increase in coincident RTs was almost twice the $S D$ for all noncoincident RT differences $(120 \mathrm{msec})$. Three of the nine errors of omission were also associated with coincident blinks that were otherwise normal, starting at $-4,+49$, and $+78 \mathrm{msec}$ in relation to the stimulus. The other six errors of omission and the one error of commission occurred with the eyes wide open, with no coincident blinks or saccades.

\section{Effect of Coincident Saccades on RTs}

The +225- to +300-msec time bin was omitted because of insufficient data. The effect of coincident saccades on RTs also varied according to when the saccade started in relation to the stimulus onset $[F(7,2359)=5.55$, $p<.001$ ] (Figure 2).

RTs were increased significantly when they were associated with coincident saccades that started within the 0 - to +75 -msec time bin (post hoc Tukey HSD, $p=.001$ ). The greatest increase in RTs was associated with saccades that started 76 to $150 \mathrm{msec}$ after the stimulus onset $(p<.001)$. The mean increase in RTs was $160 \mathrm{msec}$ - much greater than the duration of the saccades themselves, which was 


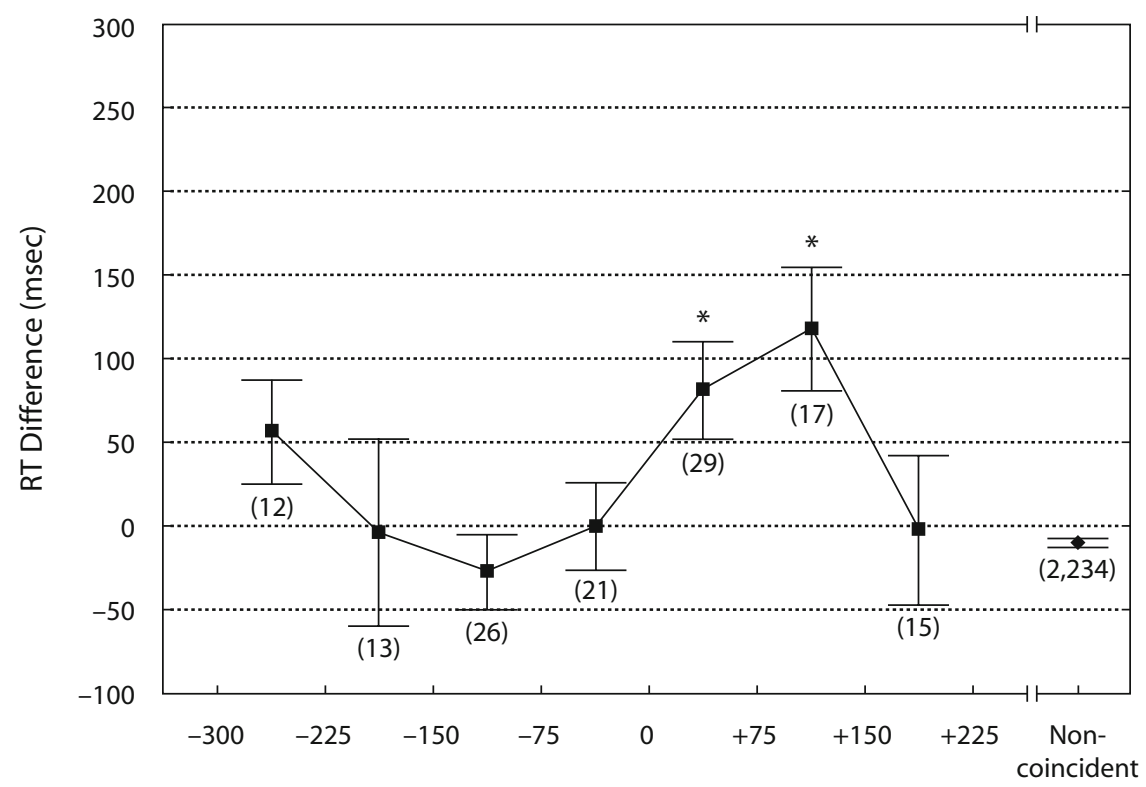

Time at Which Saccades Started in Relation to Stimulus Onset (msec)

Figure 2. The mean $( \pm S E)$ of differences between consecutive RTs that were associated with coincident and noncoincident saccades. The times that coincident saccades started are shown in relation to the stimulus onset (msec). The number of RTs in each category is shown in brackets. ${ }^{*}$ Coincident RTs that were significantly different $(p<.001)$ from noncoincident RTs, according to post hoc Tukey HSD tests. All other differences were not significant $(p>.05)$.

$59 \mathrm{msec}$ on average. There was no significant increase for saccades that started before the stimulus onset.

\section{DISCUSSION}

In the present experiment, we were concerned with spontaneous blinks and saccadic eye movements that normal people have while performing a visual RT test. We identified those blinks and saccades that happened to begin within a time window of $\pm 300 \mathrm{msec}$ around the beginning of a visual stimulus that was presented at random intervals between 5 and $15 \mathrm{sec}$. We wanted to know how RTs were affected by the timing of such ocular movements in relation to the onset of the stimulus. We removed the effects of longer term differences in RTs, within and between subjects, by comparing each RT with its immediately preceding RT within the same subject. We were concerned, therefore, with differences in RTs within the 5- to 15 -sec time frame. This is a very different experimental paradigm from that of most other researchers, who have been concerned with changes in RTs over periods of minutes, hours, or days (Bonnet, 1986; Dinges \& Kribbs, 1991).

The RT increased significantly when a blink happened to start within a time window from about $75 \mathrm{msec}$ before the stimulus until $150 \mathrm{msec}$ after the stimulus onset. As a result, many RTs increased by more than $200 \mathrm{msec}$, or about twice the $S D$ of consecutive differences between noncoincident RTs. To our knowledge, this effect has not been described previously. Even though errors of omission were infrequent, one third of them were also associ- ated with coincident blinks that started within the -75 - to +150 -msec time window.

The coincident blinks were of normal duration $(M=$ $276 \mathrm{msec}$ ) (Tucker \& Johns, 2005). If such a blink started $75 \mathrm{msec}$ before a stimulus, the upper eyelids would presumably still have covered the pupils for some time after the stimulus began. That would have prevented light entry through the pupils, delaying perception of the stimulus and increasing the RT, as we have observed. For blinks that started 75 to $150 \mathrm{msec}$ after the stimulus began, however, RTs increased by an average of $170 \mathrm{msec}$. Others have shown that a high-contrast stimulus that lasts much less than $400 \mathrm{msec}$ (e.g., $50 \mathrm{msec}$ ) can be readily responded to (Deary et al., 2004). The question arises, therefore: How does a blink that is yet to start, with the eyelids still wide open, delay the pushbutton response? We believe such an effect is entirely consistent with the process of blink suppression that is known to start about $50 \mathrm{msec}$ before the eyelid movement begins (Burr, 2005; Ridder \& Tomlinson, 1997; Volkmann et al., 1980). It is less clear how coincident blinks could have caused the errors of omission that were recorded here; however, such errors occurred infrequently, and there was not sufficient evidence to elucidate this.

There was a similar, but smaller, effect on RTs that were associated with coincident saccades. That effect was most evident when saccades happened to begin within the time window from 75 to $150 \mathrm{msec}$ after the start of the stimulus, when RTs increased by an average of $120 \mathrm{msec}$; thus, the effect of coincident saccades on RTs lasted much longer than the saccades themselves. This result is also consistent 
with the known effects of saccadic suppression (Ridder \& Tomlinson, 1997; Thiele, Henning, Kubischik, \& Hoffmann, 2002; Volkmann et al., 1968). There is no blocking of light entry to the eyes during saccades, as there is with eyelid closure during blinks. To that extent, at least, the effects of coincident saccades are different from those of coincident blinks; however, their central neural processes may share pathways (Ridder \& Tomlinson, 1997).

Our results suggest that a substantial part of the shortterm variability in RTs that is observed in normal people during a visual RT test could be caused by visual suppression that is associated with coincident ocular movements, particularly blinks and saccades. These happened about 11 times in 15 min during responses to about 85 stimuli in the present experiment. How often these occurred depended to some extent on the frequency of stimuli. Visual suppression could be expected to increase some RTs by $200 \mathrm{msec}$ or more. Visual suppression may also cause some errors of omission during studies that involve stimuli of relatively short duration, such as those that were used in the present experiment. Exactly when that would occur is largely random, depending on the "coincidence" of an ocular movement and the start of the stimulus. Others have reported that blinks tend to be inhibited during an active search phase of a visual-performance task, and then occur preferentially after a response has been made (Bauer, Strock, Goldstein, Stern, \& Walrath, 1985); however, that would presumably depend on the nature of the task and the intervals between stimuli. The blinks and saccades that were of interest here occurred during periods of anticipation of a stimulus being presented at some time within the next $15 \mathrm{sec}$. There were many blinks and saccades during those times, before and after the stimulus, and there was no evidence that their occurrence was influenced in a way that would explain our findings.

It has been known for many years that, even when people are alert, their RTs show a variability over periods of seconds that has not been fully explained. In 1931, Bills postulated a process of intermittent mental blocking to explain this phenomenon as part of normal brain function. Others have interpreted these lapses as episodes of "distraction" in an inhibition model of RTs (Burr, Morrone, \& Ross, 1994). The nature of mental blocking and how this relates to the lapses described by others (Dinges \& Kribbs, 1991; Williams et al., 1959) remains unclear, however. We suggest that visual suppression that is associated with blinks and saccades plays a significant role in the short-term variability of visual RTs and causes some lapses in psychomotor performance, in the form of long RTs (i.e., greater than $500 \mathrm{msec}$ ). If this process affects about $10 \%$ of RTs in a vigilance test, the overall mean RT might increase by about $20 \mathrm{msec}$. Whether this matters in practical terms is uncertain; however, this process may also cause some errors of omission in response to brief stimuli under normal circumstances. These effects on RT can be expected to occur in any visual test of vigilance. This may partially explain Bills's "mental blocking." Visual suppression cannot explain all the variability in RTs or the errors of omission that we observed in alert subjects, however. There are presumably other mechanisms involved, including changes in the ability to focus and maintain other aspects of visual attention, and the effects of noise in neural integrators that are involved in the perceptual decision-making process (Shadlen \& Newsome, 2001; Woodman, Kang, Thompson, \& Schall, 2008).

We can only speculate whether this matters in real-life situations, in which it is normal to have periods of lack of awareness that last 100-200 msec associated with blinks and saccades that go unnoticed. The visual stimulus that was used here was achromatic, with a relatively low spatial but high temporal frequency. Presumably, this would have been processed by the magnocellular visual system, which is known to be very susceptible to blink and saccadic suppression (Bristow et al., 2005; van der Ven, Smit, \& Jansen, 1989). This kind of visual information is important in many real-life situations, and a $200-\mathrm{msec}$ or greater increase in visual RTs may be critically important in some of them. For example, a driver who is traveling at $100 \mathrm{~km} / \mathrm{h}$ and applies the brakes in an emergency would travel $5.6 \mathrm{~m}$ further as a result of a 200-msec increase in RT. This may well be significant in terms of road safety, if not causing an increase in the frequency of crashes nevertheless causing an increase in the severity of their consequences because of higher impact velocity.

\section{AUTHOR NOTE}

Correspondence related to this article should be addressed to M. Johns, Optalert Pty Ltd, Suite 9, 150 Chestnut Street, Richmond, Melbourne, VIC 3121, Australia (e-mail: mjohns@optalert.com).

\section{REFERENCES}

Bauer, L. O., Strock, B. D., Goldstein, R., Stern, J. A., \& WalRATH, L. C. (1985). Auditory discrimination and the eyeblink. Psychophysiology, 22, 636-641.

BILls, A. G. (1931). Blocking: A new principle of mental fatigue. American Journal of Psychology, 43, 230-245.

Bonnet, M. H. (1986). Performance and sleepiness as a function of frequency and placement of sleep disruption. Psychophysiology, 23, 263-271.

Brebner, J. M. T., \& Welford, A. T. (1980). Introduction: An historical background sketch. In A. T. Welford \& J. M. T. Brebner (Eds.), Reaction times (pp. 1-23). New York: Academic Press.

Bristow, D., Haynes, J.-D., Sylvester, R., Frith, C. D., \& Rees, G. (2005). Blinking suppresses the neural response to unchanging retinal stimulation. Current Biology, 15, 1296-1300.

BurR, D. [C.] (2005). Vision: In the blink of an eye. Current Biology, 15, R554-R556.

Burr, D. C., Morrone, M. C., \& Ross, J. (1994). Selective suppression of the magnocellular visual pathway during saccadic eye movements. Nature, 371, 511-513.

Deary, I. J., Simonotto, E., Meyer, M., Marshall, A., Marshall, I., GodDARD, N., \& WARDLAW, J. M. (2004). The functional anatomy of inspection time: An event-related fMRI study. NeuroImage, 22, 1466-1479.

Diamond, M. R., Ross, J., \& Morrone, M. C. (2000). Extraretinal control of saccadic suppression. Journal of Neuroscience, 20, 34493455 .

Dinges, D. F., \& KriBBs, N. B. (1991). Performing while sleepy: Effects of experimentally-induced sleepiness. In T. H. Monk (Ed.), Sleep, sleepiness and performance (pp. 97-128). New York: Wiley.

Donders, F. C. (1969). On the speed of mental processes. In W. G. Koster (Ed.), Attention and performance II (pp. 412-431). Amsterdam: North-Holland. (Original work published 1868)

Eriksen, B. A., \& EriKsen, C. W. (1974). Effects of noise letters upon the identification of a target letter in a nonsearch task. Perception \& Psychophysics, 16, 143-149. 
Johns, M. W., Tucker, A. [J.], Chapman, R., Crowley, K., \& MiCHAEL, N. [J.] (2007). Monitoring eye and eyelid movements by infrared reflectance oculography to measure drowsiness in drivers. Somnologie, 11, 234-242.

LEIGH, R. J., \& ZEE, D. S. (2006). The neurology of eye movements. Oxford: Oxford University Press.

LuCE, R. D. (1986). Response times: Their role in inferring elementary mental organization. New York: Oxford University Press.

Posner, M. I., Snyder, C. R., \& Davidson, B. J. (1980). Attention and the detection of signals. Journal of Experimental Psychology: General, 109, 160-174.

RidDER, W. H., III, \& Tomlinson, A. (1997). A comparison of saccadic and blink suppression in normal observers. Vision Research, 37, 3171-3179.

Shadlen, M. N., \& Newsome, W. T. (2001). Neural basis of a perceptual decision in the parietal cortex (area LIP) of the rhesus monkey. Journal of Neurophysiology, 86, 1916-1936.

Thiele, A., Henning, P., Kubischik, M., \& Hoffmann, K.-P. (2002). Neural mechanisms of saccadic suppression. Science, 295, 24602462.

Tucker, A. J., \& Johns, M. W. (2005). The duration of eyelid movements during blinks: Changes with drowsiness. Sleep, 28, A122.
Van Breukelen, G. J. P., Roskam, E. E. C. I., Eling, P. A. T. M., Jansen, R. W. T. L., Souren, D. A. P. B., \& Ickenroth, J. G. M. (1995). A model and diagnostic measures for response time series on tests of concentration: Historical background, conceptual framework, and some applications. Brain \& Cognition, 27, 147-179.

Van der Ven, A. H. G. S., Smit, J. C., \& Jansen, R. W. T. L. (1989). Inhibition in prolonged work tasks. Applied Psychological Measurement, 13, 177-191.

Volkmann, F. C., Riggs, L. A., \& Moore, R. K. (1980). Eyeblinks and visual suppression. Science, 207, 900-902.

Volkmann, F. C., Schick, A. M., \& Riggs, L. A. (1968). Time course of visual inhibition during voluntary saccades. Journal of the Optical Society of America, 58, 562-569.

Williams, H. L., Lubin, A., \& Goodnow, J. J. (1959). Impaired performance with acute sleep loss. Psychological Monographs, 73, 1-26.

Woodman, G. F., Kang, M.-S., Thompson, K., \& Schall, J. D. (2008). The effect of visual search efficiency on response preparation: Neurophysiological evidence for discrete flow. Psychological Science, 19, 128-136.

(Manuscript received August 12, 2008;

revision accepted for publication November 29, 2008.) 